\title{
Effect of preferred learning styles on academic achievements: A cross sectional descriptive study.
}

1. M.Phil, MBBS

Assistant Professor Physiology Fatima Jinnah Medical University Lahore.

2. FCPS II (PGR), M.Phil, MBBS Assistant Professor Physiology $\mathrm{CMH}$ Medical \& Dental College Lahore.

3. FCPS (Physiology), MBBS Demonstrator Physiology The University of Faisalabad.

4. M.Phil, MBBS

Assistant Professor Physiology Al Aleem Medical College Lahore.

5. M.Phil, MBBS

Demonstrator Physiology

Fatima Jinnah Medical University Lahore.

6. M.Phil, MBBS

Assistant Professor Physiology Niazi Medical \& Dental College Sargodha.

Correspondence Address:

Dr. Maryam Rao

Department of Physiology

Fatima Jinnah Medical University

Lahore.

dr.maryamrao@gmail.com

Article received on:

17/07/2020

Accepted for publication:

04/01/2021

\section{INTRODUCTION}

Medical students have their own strengths in adopting different learning style preferences. The process by which a learner can effectively perceive, understand, memorize and recall a specific piece of information is called the 'learning style. ${ }^{1}$ The learning style of one person is different from the other because of the differences in the cognitive skills that vary from person to person. It is very important that the learning styles and retention of knowledge is improved to keep students motivated for handling future challenges related to increased difficulty index of any particular subject. There are many ways to assess the learning style preferences. In this study the Visual, Auditory, Read/Write/ Kinesthetic (VARK) Questionnaire tool is used to assess the learning style preferences. According to Fleming, who launched the VARK model in 1987, it is the best tool used for assessment of most preferred learning style by the learner. ${ }^{2}$ Incorporating VARK for observing the learning style preferences means that sensory modality preferences of the student are being taken into consideration. This assessment of sensory modality preference promotes self-awareness in the students and help them adopt the learning style that can benefit them to the maximum extent. ${ }^{3}$

Few students use one or two modes for learning while others use multimodal techniques, incorporating almost a combination or all the modes to improve learning and achieve better results. ${ }^{4}$

To develop a good understanding towards a 
subject and perform better, it is a must that the students identify their learning style preferences. This is how they can learn more within a shorter duration of time. ${ }^{5}$ The modes of instruction can be modified according to the preferred learning style of the students so that they can be motivated enough to achieve even better. ${ }^{6}$ While using the VARK assessment tool, students who prefer 'V' have a special capability to understand the diagrams and graphs. They are more inclined to learn by observing the presentation of the text showing a special interest in observing the figures and bar graphs. Learners who select ' $A$ ' can learn more by taking lectures, presentations, discussions or by going through the subject by listening to peers or through recorded lectures. ' $R$ ' is the sensory modality by which the student goes through the written content and learns better by reading or writing, handling with the text or printed material. ' $\mathrm{K}$ ' means kinesthetic ability in which the student learns best by some practical demonstration of the subject or by performing some related activity by him/herself. ${ }^{3,6}$ It means that the students who use $\mathrm{K}$ prefer to know the application of the particular subject being taught. Students show a great variation not only in their preferred choice but also the way in which they use a uni-modal or a multimodal technique..$^{3,6}$

Physiologystudents are selected duetothesubject difficulty and convenience of data collection. The purpose of the study is to find if majority of the undergraduate Physiology students use visual, aural, read/write or kinesthetic learning styles and the effect of learning style preferences on the academic achievement of the students.

VARK questionnaire scoring will not only help students to become more aware of themselves and improve their modes of learning but it will also be helpful in faculty development. By altering and matching teaching modalities with the most preferred learning styles of the students, the diverse and growing needs of the students can be served.

\section{MATERIAL \& METHODS}

This is a cross sectional, descriptive quantitative study carried out in Department of Physiology of
Fatima Jinnah Medical University from December 2018 till June 19. In order to get an access to the academic record of the $2^{\text {nd }}$ year MBBS students of FJMU, written and verbal consent was taken from the Head of Physiology Department and the Registrar of the Medical University. After approval from Ethical Review Board of the institution (24-Resh Proposal Physio/FJ), a study was conducted by administering the questionnaire to 170 , out of a total of 300 undergraduate MBBS $2^{\text {nd }}$ year female Physiology students by simple random selection. In random selection, sample size can generalize the results as sufficient sample is taken from a larger population and each individual has an equal chance of being selected. For this study sample size was calculated by keeping the confidence level at 95\% and margin of error at $5 \%$. Written consent was taken from the students, after giving them proper information regarding the purpose of study and taking full responsibility that the confidentiality of their data will be maintained. All the consented, voluntary students who had attended the lectures, practical classes and tutorials regularly (attendance $>75 \%$ ), were included in the study. Different teaching modalities were being used with these students like delivery of lectures, power point presentations with audiovisual effects, small group discussions and interactive sessions, problem solving questionnaires, tutorials and practicals.

The VARK questionnaire (Version 7.1) developed by Fleming was administered to the students. This is a valid tool to assess the learning style preferences of students. VARK questionnaire is selected because of its free availability and simplicity of usage. It consists of 16 questions having four options each. The students can select more than one option to answer the questions. The most important part of the questionnaire is that it includes a scoring chart, so the students can calculate their own scores at the end, which enables them to identify their learning style preferences.

The academic record of the students included the results of all the four written tests which were taken periodically in the academic year 
of $2^{\text {nd }}$ year MBBS. The aggregate percentage was calculated and divided into four categories i.e, $0-25 \%, 26-50 \%, 51-75 \%$ and $76-100 \%$. The academic achievement (aggregate percentage range) of the included students was matched with their learning style preferences that was identified by using the scoring chart at the end of VARK questionnaire. A relationship between the learning style preferences and academic achievement was studied by applying inferential analysis. The data was analyzed by using SPSS version 23.0.

\section{RESULTS}

Learning style preferences of the students is shown in a tabulated form in frequency Table-I.

\begin{tabular}{|c|c|}
\hline VARK (Preference) & Frequency \\
\hline V & 27 \\
\hline$A$ & 51 \\
\hline $\mathrm{R}$ & 19 \\
\hline $\mathrm{K}$ & 73 \\
\hline Total & 170 \\
\hline
\end{tabular}

Table-I shows that out of a total of 170 students, 27 preferred visual method, 51 aural, 19 read and write while 73 students preferred kinesthetic method as their first choice for learning. It means that around $43 \%$ of the included students used kinesthetic modality of sensation for their learning. These students preferred to learn by practical application of knowledge or some kind of related activity.

The distribution of VARK learning styles and academic achievement is shown in Table-II.

\begin{tabular}{|l|c|c|c|c|c|}
\hline $\begin{array}{c}\text { Learning Style } \\
\text { Preference }\end{array}$ & \multicolumn{4}{|c|}{$\begin{array}{c}\text { Academic Achievement } \\
\text { (Percentage range \%) }\end{array}$} & Total \\
\hline & $\mathbf{0 - 2 5}$ & $\mathbf{2 6 - 5 0}$ & $\mathbf{5 1 - 7 5}$ & $\mathbf{7 6 - 1 0 0}$ & \\
\hline Visual & 0 & 3 & 21 & 3 & 27 \\
\hline Aural & 0 & 4 & 38 & 9 & 51 \\
\hline Read & 1 & 0 & 15 & 3 & 19 \\
\hline Kinesthetic & 1 & 11 & 55 & 6 & 73 \\
\hline Total & 2 & 18 & 129 & 21 & 170 \\
\hline
\end{tabular}

Professional Med J 2021;28(11):1673-1677.
Table-Il clearly shows that the maximum number of selected students fell between academic achievement percentage range $51-75 \%$ and out of 129 students falling in this score range, 55 preferred kinesthetic while 38 preferred aural modality of sensation. Only 21 out of 170 students achieved percentage in the range of 76-100 in their internal assessments. These high achievers preferred aural and kinesthetic way of learning.

Pearson Chi Square test was applied to find an association, if exists, between the learning style preferences and academic achievement.

\begin{tabular}{|l|c|c|c|}
\hline & Value & df & $\begin{array}{c}\text { Signif- } \\
\text { icance }\end{array}$ \\
\hline Pearson Chi-square & 4.915 & 9 & 0.842 \\
\hline Likelihood ratio & 5.762 & 9 & 0.763 \\
\hline Linear by linear association & 0.362 & 1 & 0.547 \\
\hline N of valid cases & 170 & & \\
\multicolumn{2}{|c|}{ Table-III. Inferential analysis table. }
\end{tabular}

Table-III is the inferential analysis table, in which sample data is taken and prediction about the whole class is made. No significant relationship could be found between learning styles preferences and academic achievements of the students.

\section{DISCUSSION}

The students who are more aware of their capabilities, perform better. Self-regulated learning of students can be enhanced by making them aware of their strengths and this leads to increased self-efficacy. ${ }^{7}$ Similar to the findings of our study, a study conducted by Prithishkumar also elaborated that there is no association between the academic achievement and learning style preferences but kinesthetic method is the most preferred method of learning among the students. ${ }^{8}$ Other studies done in this regard also pointed towards the fact that a preferred learning style always dominates a student depending upon his educational background. A study conducted by Balasubramaniam et al in 2016 also showed kinesthetic method as the most predominant one. ${ }^{9}$ In 2017, Daniel et al conducted a study, which also strengthened the fact that the knowledge of a preferred learning style can help 
the student achieve better. ${ }^{10}$ However, association of academic achievement and learning style preference is still unknown. ${ }^{9,10}$

Based on the results at the end of VARK questionnaire, the students become more aware of themselves. The students can improve their modes of learning and can use other sensory modalities too, to maximize success and improve academic achievements at individual level.

This study is also helpful in faculty development. By altering the teaching modalities and matching these modalities with the most preferred learning styles of majority of the students, the diverse and growing needs of the students can be served.

\section{CONCLUSION}

Most preferred learning styles according to this study are kinaesthetic and aural. The students should be given more opportunities to see demonstrations and practically perform the procedures. Use of models and problem solving questionnaires can be helpful. Delivering the lectures and allowing the students to record them along with small group discussion sessions will help the students with aural mode as their preferred learning style. This study will also help teachers find ways by which the students can be guided to achieve better.

\section{Copyright $@ 04$ Jan, 2021.}

\section{REFERENCES}

1. Almigbal TH. Relationship between the learning style preferences of medical students and academic achievement. Saudi Med J. 2015; 36(3): 349-55. DOI: 10.15537/smj.2015.3.10320.
2. Fleming N, Baume D. Learning Styles Again: VARKing up the right tree!. Educational developments. 2006 Nov $4 ; 7(4): 4$.

3. Wehrwein EA, Lujan H, Di Carlo L. Gender differences in learning style preferences among undergraduate Physiology students. Adv Physiol Educ.2007; 31:1537. https://doi.org/10.1152/advan.00060.2006

4. Akhlaghi $\mathrm{N}$, Mirkazemi $\mathrm{H}$, Jafarzade $\mathrm{M}$, Akhlaghi $\mathrm{N}$. Does learning style preferences influence academic performance among dental students Isfahan, Iran. J Educ Eval Health Prof. 2018; 15:8. doi: 10.3352/ jeehp.2018.15.8.

5. Othman N, Amiruddin MH. Different perspectives of learning styles from VARK model. Procedia. 2010; 7:652-60. https://doi.org/10.1016/j.sbspro.2010.10.088.

6. Awang H, Samad N, Faiz N,Roddin R, Kankia JD. Relationship between learning styles preferences and academic achievements. 2017 IOP Conf. Ser.: Mater. Sci. Eng. 226 012193. doi:10.1088/1757899X/226/1/012193.

7. Agustiani H, Cahyad S, Musa M. Self-efficacy and self-regulated learning as predictors of students' academic performance. TOPSYJ. 2016; 9:1-6. DOI: $10.2174 / 1874350101609010001$.

8. Prithishkumar IJ, Michael SA. Understanding your student: Using the VARK model. J. Postgrad. Med. 2014; 60(2):183-6. DOI: 10.4103/0022-3859.132337.

9. Balasubramaniam G, Indhu K. A study of learning style preferences among first year undergraduate medical students using VARK model. Education in Medicine Journal. 2016; 8(4):15-21.

10. Hernández-Torrano D, Ali S, Chan CK. First year medical students' learning style preferences and their correlation with performance in different subjects within the medical course. BMC Med Educ. 2017 ; 17(1):131. DOI: 10.1186/s12909-017-09655. 


\begin{tabular}{|c|l|l|l|}
\hline \multicolumn{3}{|c|}{ AUTHORSHIP AND CONTRIBUTION DECLARATION } \\
\hline No. & \multicolumn{1}{|c|}{ Author(s) Full Name } & \multicolumn{1}{|c|}{ Contribution to the paper } & Author(s) Signature \\
\hline 1 & Maryam Rao & $\begin{array}{l}\text { Planning and conduction of } \\
\text { research. } \\
\text { Data analysis. }\end{array}$ \\
\hline 2 & Qudsia Umara Khan & $\begin{array}{l}\text { Review and finalization of } \\
\text { manuscript. } \\
\text { Initial manuscript writing. }\end{array}$ \\
\hline 5 & Sana Akram & Wardah Anwar & Data collection. \\
6 & Thazo Sana & Proof reading. & \\
\hline
\end{tabular}

